\title{
La ley de Hume en Hume: la discusión de la interpretación analítica de Treatise III, 1, i
}

\author{
Hume's Law in Hume: The Discussion \\ on the Analytical Interpretation of Treatise III, $1, i$
}

\author{
Felipe WIDOW LIRA* \\ Pontificia Universidad Católica de Chile (Chile) \\ ffwidow@uc.cl
}

Recibido: 06/11/2014

Aceptado: 30/04/2015

\section{Resumen}

La regla lógica que prohíbe inferir conclusiones morales o normativas desde premisas fácticas fue atribuida a David Hume por los primeros autores analíticos que se ocuparon de esta cuestión (Hare, Prior, Nowell-Smith), llegando a ser conocida, esta regla, como la ley de Hume. Sin embargo, esta atribución ha sido fuertemente discutida desde entonces. El propósito de este trabajo es sistematizar los argumentos de esta discusión desde su origen -que se encuentra en un trabajo de A.C. MacIntyrehasta la intervención de J.M. Finnis, en razón de que en tal período, aunque no se cierra la discusión en cuestión, quedan ya enunciados todos los problemas centrales que envuelve la interpretación del texto de Hume.

Palabras clave: cuestión ser-deber ser, ética analítica, Hume, ley de Hume, razón práctica.

\begin{abstract}
The logical rule which forbids inferring moral or normative conclusions from factual premises was attributed -by the first analytical authors who dealt with this issue (Hare, Prior, Nowell-Smith)- to David Hume, getting to be known as Hume's Law. However, since then, this attribution has been strongly contested. The purpose of this paper is to systematize the arguments of this discussion from its origin -in a

\footnotetext{
* Para el desarrollo de esta investigación se ha contado con el apoyo de CONICYT - Chile, mediante la concesión de una Beca Chile para estudios de doctorado en el extranjero.
} 
work of A.C. MacIntyre- until the intervention of J.M. Finnis. The reason for this is that all the core problems surrounding the interpretation of the text of Hume are already stated -even though the discussion in question is not closed.

Keywords: is-ought question, analytical ethics, Hume, Hume's law, practical reason.

\section{Sumario:}

1. Introducción

2. Inferencia, deducción y significado del 'debe'

3. El deber como hecho

4. El pasaje del 'is' y el 'ought' en el contexto de Treatise III, i, 1: la razón no mueve a la acción ni es causa de la obligación

5. Breve nota conclusiva.

\section{Introducción}

Como es bien sabido, la ley de Hume se refiere a la imposibilidad lógica de inferir el deber ser a partir del ser, inferencia que muchos críticos imputan al iusnaturalismo. Esto ha generado un nutrido debate, tanto sobre la pertinencia de dicha imputación como sobre la validez lógica de la ley de Hume. Ahora bien, en esta discusión se ha interpuesto un segundo problema, sobre una cuestión que no toca al fondo de la discusión primera pero que, no obstante, es singularmente valiosa -de un modo indirecto- para la comprensión de los argumentos que están en juego en aquella discusión: se trata de la asociación de la ley de Hume con el propio Hume, puesto que, aunque los defensores analíticos de esta ley refieren su primera formalización a un texto del filósofo escocés, se ha cuestionado que su formulación contemporánea corresponda a la mente y a la intención filosófica del empirista del xVIII. Por ello, el estudio de esta discusión es muy iluminador respecto de las pre-comprensiones que están implícita o explícitamente asumidas en cada una de las soluciones interpretativas de la obra moral de Hume. El propósito de este trabajo es sistematizar el contenido de esta discusión desde sus orígenes -situados en un artículo de A.C. MacIntyre de 1959- hasta la intervención John Finnis -en su opera magna: Natural Law and Natural Rights, de 1980-, no porque con esta última intervención se cierre la discusión, sino porque en tal período quedan ya enunciadas todas las cuestiones o problemas que plantea la interpretación de Hume en esta materia.

El texto del escocés por el cual le ha sido atribuida la ley en cuestión se halla en A Treatise of Human Nature, y su contenido es el siguiente:

En todos los sistemas de moralidad que he encontrado hasta ahora, he notado siempre que el autor procede por algún tiempo según el modo ordinario de razonar y 
establece la existencia de Dios, o hace observaciones sobre las cosas humanas; mas súbitamente me sorprendo al encontrar que, en lugar de las cópulas habituales de las proposiciones, es-no es, no encuentro ninguna proposición que no esté enlazada por un debe-no debe. Este cambio es imperceptible, pero de graves consecuencias, porque este debe-no debe expresa una nueva relación, que ha de ser observada y explicada; $y$, al mismo tiempo, porque debe darse una razón para algo que parece completamente inconcebible: cómo esta nueva relación puede ser una deducción de otras que son enteramente diferentes de ella ${ }^{1}$.

El propósito de Hume, según autores como $\mathrm{Hare}^{2}$, Prior $^{3}$ o Nowell-Smith ${ }^{4}$, sería señalar la imposibilidad de la deducción de juicios cuya cópula es un debe a partir de premisas cuya cópula es un es (por ello, la frase "parece completamente inconcebible", que usa el escocés en el texto en cuestión, sería irónica, y significaría "es completamente inconcebible"), imposibilidad que cobraría especial relevancia -en la filosofía del escocés- si se atiende al supuesto de que todo argumento, si no es deductivo, resulta inevitablemente defectuoso. Así, atendidas estas dos premisas, debería necesariamente concluirse que, entre una descripción de hecho -que, según estos autores, sería el caso central de las is-propositions- y un juicio de valor o normativo -caso central, a su vez, de las ought-propositions- hay, siempre y necesariamente, un salto lógico absolutamente insalvable.

Ahora bien, esta interpretación del texto del Tratado sobre la naturaleza humana, que en la primera mitad del siglo xx fue casi canónica ${ }^{5}$, ha sido fuertemente puesta en cuestión a partir de la segunda mitad del mismo siglo. Y si aquellos analíticos afirmaban -como doctrina de Hume- que no puede haber consecuencia lógica del es al debe, los críticos de esta lectura afirmarán que, muy por el contrario, lo que el escocés estaría diciendo en aquél pasaje es que aquella consecuencia existe, pero que debe ser adecuadamente explicada, cosa que no han hecho los autores morales que le precedieron. Por supuesto, antes del debate que se reseñará en estas páginas, ya habían surgido voces disidentes respecto de la interpretación analítica de este pasaje de Hume. Arnold Brecht,

\footnotetext{
${ }^{1}$ David Hume. A Treatise of Human Nature, III, i, 1. Se emplea la edición de L. A. Selby-Bigge, Clarendon Press, Oxford, 1896. Todas las traducciones presentes en este trabajo son propias, salvo que se indique expresamente lo contrario.

${ }^{2}$ Vid. R. M. Hare. El lenguaje de la moral. Traducción de Genaro Carrió y Eduardo Rabossi, UNAM, México, 1975, p. 38.

${ }^{3}$ Vid A. N. Prior. Logic and the Basis of Ethics. Clarendon Press, Oxford, 1949, p. x y 32-33.

${ }^{4}$ Vid. P. H. Nowell-Smith. Ética. Traducción de Gilberto Gutiérrez López, Editorial Verbo Divino, Estella (Navarra), 1977, pp. 52-53.

${ }^{5}$ Por razón de simplicidad, llamaremos a esta interpretación interpretación analítica, puesto que surge en el seno del movimiento analítico y a él pertenecen sus principales defensores. No obstante, es necesario advertir que en este nombre hay una generalización impropia, puesto que la pertinencia de la atribución a Hume de la ley que lleva su nombre también ha sido discutida entre los propios analíticos, lo mismo que la validez de la regla lógica en la que consiste.
} 
por ejemplo, en un artículo de 1941, excluye al escocés de los orígenes de la doctrina sobre la cesura lógica entre ser y deber ${ }^{6} \mathrm{y}$, en una obra posterior -su, ya clásica, Teoría Política. Los fundamentos del pensamiento político del siglo xx-, dedica una página y media -en uno de los apéndices- a justificar esta exclusión ${ }^{7}$. No obstante, sólo a partir de un artículo publicado por A. C. MacIntyre, en 1959, se desarrollará un debate crítico sistemático sobre la propiedad de la interpretación analítica.

Las líneas argumentales que abrieron la discusión sobre esta cuestión son dos: la primera consiste en negar el supuesto de que, en Hume, cualquier argumento que no sea deductivo resulta necesariamente defectuoso, de manera que el pasaje en cuestión se puede entender en términos de inferencia -más que de deducción-, a la vez que se niega el carácter irónico -sostenido por los analíticos- de la frase "parece completamente inconcebible". De este modo, el texto de Hume vendría a decir que, aunque parece inconcebible, es posible una inferencia del ser al deber, que ha de ser explicada. La segunda línea argumental -para una interpretación contraria a la analítica- acepta el supuesto de que los argumentos no deductivos son defectuosos pero, en cambio, rechaza aquél de que no se deduce el deber a partir de cuestiones de hecho. O, más bien, la admite pero con reparos: sería imposible la deducción del deber a partir del ser tal como lo intentan los sistemas de moral que critica Hume; pero sería, en cierto sentido, posible tal deducción si se entiende adecuadamente la misma noción de deber -o lo que Hume entendía por ella-. La clave de esta interpretación consiste en la reducción de los juicios unidos por la cópula debe a enunciados de hecho, que no hacen más que informar de una emoción o sentimiento, que es la que se expresa con la cópula debe. Esta reducción es la que no habrían explicado los autores que precedieron a Hume y a los que el escocés dirigiría su crítica.

\section{Inferencia, deducción y el significado del 'debe'}

Como ya se ha advertido, el autor que inicialmente trajo a la palestra la primera de las lecturas recién reseñadas fue el entonces profesor de la Universidad de Essex: A. C. MacIntyre, en un artículo de 1959 titulado "Hume on 'Is' and 'Ought""

La interpretación de MacIntyre se compone de un supuesto contextual y dos proposiciones interpretativas conectadas entre $\mathrm{si}^{9}$. El supuesto contextual consiste en la afirmación de que el texto de Hume en cuestión no puede ser leído como si expresase la intención del filósofo escocés de afirmar la autonomía de la moral, porque tal

\footnotetext{
${ }^{6}$ Vid. Arnold Brecht. "The Myth of Is and Ought", en Harvard Law Review vol. LIV, n 5, 1941, pp. 811-831.

${ }^{7}$ Vid. Arnold Brecht. Teoría política. Los fundamentos del pensamiento político del siglo xx. Traducción de Juan Manuel Mauri, Ariel, Barcelona, 1963, pp. 553-555.

${ }^{8}$ A. C. MacIntyre. "Hume on 'Is' and 'Ought'", en The Philosophical Review vol. LXVIII, n 4, 1959, pp. 451-468.

${ }^{9}$ Vid. A. C. MacIntyre. "Hume on 'Is' and 'Ought””, pp. 465-466.
} 
intención no está de ningún modo presente en la obra ética completa del autor. Las proposiciones interpretativas, en tanto, son las siguientes: primera, aunque Hume emplea la expresión "deducción" (deduction), esta no debe ser entendida en sentido estricto -como significando "implicación lógica" (entailment)-, sino en sentido amplio -esto es, significando "inferencia" (inference)-; segunda, Hume sostendría la posibilidad de inferir el deber a partir del ser en la medida en que tal inferencia esté mediada por algún concepto que exprese lo que Hume entendía como pasiones.

Para demostrar que Hume no tiene en su horizonte la pretensión de afirmar la autonomía de la moral, MacIntyre recurre a una serie de pasajes en los que se manifestaría claramente el hecho de que la regla moral se justifica mediante una constatación fáctica. El ejemplo más claro sería el de la teoría humeana de la justicia. MacIntyre cita el siguiente texto del escocés:

[A]unque los actos singulares de justicia puedan ser contrarios tanto al interés público como al privado, lo cierto es que el plan o esquema completo [de las reglas de justicia] es extremadamente útil y, de hecho, absolutamente necesario para la conservación de la sociedad y para el bienestar de cada individuo. Es imposible separar el bien del mal. La propiedad debe ser estable, y debe estar fijada por reglas generales. Aunque en alguna instancia sufra el interés público, este mal momentáneo se halla ampliamente compensado por el cumplimiento continuo de la regla, y por el estado de paz y orden que ella establece en la sociedad ${ }^{10}$.

En opinión de MacIntyre, en un texto como este Hume presupone que, en sentido lógico, es apropiado justificar las reglas de justicia por su referencia a las condiciones de hecho para el interés público ${ }^{11}$, a la vez que afirma que, en sentido moral, las reglas de justicia tienen auténtico valor imperativo cuando, también de hecho, sirven a ese interés público: "debemos obedecer las reglas porque no hay nadie que no gane más de lo que pierde por esa obediencia" 12 . En otras palabras, este tipo de argumentación revelaría que el escocés reconoce una relevancia lógica de los hechos para la formulación de los juicios morales ${ }^{13}$ y que, en consecuencia, se aparta decidi-

\footnotetext{
${ }^{10}$ David Hume. A Treatise of Human Nature, III, ii, 2.

${ }^{11}$ Vid. A. C. MacIntyre. "Hume on 'Is' and 'Ought'", p. 457.

${ }^{12}$ Ibid.

${ }^{13}$ Esta tesis de MacIntyre sería duramente criticada por R. F. Atkinson [Vid. R. F. Atkinson. "Hume on 'Is' and 'Ought': A Replay to Mr. MacIntyre”, en The Philosophical Review vol. LXX, n 2, 1961, pp. 231-238], quien lo acusa de confundir dos modos de entender la autonomía de la moral: hay un sentido estricto, dice, según el cual "no es posible que conclusiones morales estén lógicamente implicadas (entailed) en premisas no morales" [p. 232], y otro amplio que implicaría que "las situaciones fácticas son lógicamente irrelevantes (en un sentido más fuerte que el de 'no implicadas lógicamente') para los juicios morales" [Ibid.]. El sentido amplio envuelve al estricto, pero no sucede lo mismo en sentido inverso. Así, pues, al negar que Hume sea un autonomista en el segundo sentido, no se niega que lo sea en el primero.
} 
damente de las tesis "autonomistas", que afirman, por el contrario, la irrelevancia de los hechos para la constitución de aquellos juicios ${ }^{14}$.

Ahora bien, más allá de la cuestión contextual de la autonomía de la moral, se decía que la reinterpretación propuesta por MacIntyre se fundaba en dos supuestos: el sentido amplio con que empleaba -Hume, en el texto en cuestión- el término "deducción" (deduction), por una parte; y la posibilidad -en el contexto general de la ética del escocés- de inferir el deber a partir del ser, por la otra.

El primero de estos supuestos es el más difícil de demostrar y el menos relevante para estas páginas: tanto MacIntyre como sus críticos traen a colación diversos argumentos, ya para afirmar que el uso habitual de deduction en el siglo XVIII era el de inference (posición de MacIntyre ${ }^{15}$ ), ya para sostener que el uso que Hume daba a este concepto en el texto discutido era estricto, y se debe leer en términos de entailment (posición de Atkinson, Flew, Hudson y demás críticos de MacIntyre ${ }^{16}$ ). Habiendo base suficiente para cualquiera de las dos lecturas, la cuestión no puede resolverse por sí misma, sino que se debe mirar a la coherencia de una u otra posición con el contexto de la filosofía moral de Hume. Y aquí es donde cobra especial relevancia el segundo de los supuestos en los que el profesor de Essex funda su reinterpretación: la posibilidad, para Hume, de inferir el deber a partir del ser.

Entendida la voz deduction como inferencia, MacIntyre sostiene que es posible inferir cuáles son nuestros deberes a partir de juicios de hecho. La transición entre el ser y el deber la hace, Hume -según el profesor de Essex-, mediante el recurso a algún concepto que sirva de puente entre el 'es' y el 'debe', y los conceptos que pueden servir de tal puente son aquellos que expresan una materia de hecho que otorga un motivo o razón para actuar, y las materias de hecho que otorgan tal motivo o razón son las pasiones. Por ello, cualquier concepto que exprese necesidad, deseo, querer, etc., permitirá hacer la transición desde un juicio de hecho hasta un juicio de deber ${ }^{17}$. Otra vez se prestaría la teoría humeana de la justicia como ejemplo nítido de esto: como ya se advierte en el texto de Hume antes citado ${ }^{18}$, el orden de la justicia sólo tiene sentido en la medida de su utilidad para el interés público y privado, cosa que el escocés afirma explícitamente en varios lugares, como los que siguen: "[i]ncrementa en un grado suficiente la bondad de los hombres o la liberalidad de la naturaleza, y

\footnotetext{
${ }^{14}$ A pesar de la crítica de Atkinson, el profesor de Cambridge, M. J. Scott-Taggart, se suma a la opinión de MacIntyre en este punto: "[1]a sección de la cual está tomado este pasaje se llama 'Las distinciones morales no se derivan de la razón' y, en él, Hume argumenta con gran claridad contra la autonomía de la moral” M. J. Scott-Taggart. "MacIntyre's Hume”, en The Philosophical Review vol. 70, nº 2, 1961, p. 239.

${ }^{15}$ Vid. A. C. MacIntyre. "Hume on 'Is' and 'Ought"”, p. 460-461.

${ }^{16}$ Vid. R. F. Atkinson. "Hume on 'Is' and 'Ought': A Replay to Mr. MacIntyre", pp. 235-236; W. D. Hudson. La filosofía moral contemporánea. Traducción de José Hierro, Alianza Editorial, Madrid, 1974, pp. 243-244.

${ }^{17}$ Vid. A. C. MacIntyre. "Hume on 'Is' and 'Ought'”, pp. 462-466.

${ }^{18}$ David Hume. A Treatise of Human Nature, III, ii, 2.
} 
harás inútil la justicia, y su lugar sería ocupado por virtudes más perfectas y bienes de más valor" ${ }^{\prime 19}$. Y poco más adelante:

Es evidente que la única causa de que la justicia sea destruida por una gran generosidad del hombre, o por la gran abundancia de alguna cosa, es que la hacen inútil; y es también evidente que, por otra parte, la bondad limitada del hombre y su condición de necesidad dan lugar a esta virtud sólo en cuanto que la hacen necesaria para el interés público y de cada individuo ${ }^{20}$.

Esta utilidad, sostiene Hume, la descubrimos en la experiencia de la imposibilidad de alcanzar nuestro propio interés si no es de algún modo moderado el egoísmo, que nos entrega a una lucha de intereses autodestructiva. Tal experiencia engendra en nosotros un sentimiento de necesidad: la de generar las condiciones para que mi interés privado sea posible, no obstante la oposición que encuentra en el egoísmo desatado y la generosidad limitada de los hombres ${ }^{21}$. Tales condiciones se dan en la medida de la confluencia del interés privado con un interés común, de manera que aquella necesidad engendrada por el deseo del propio bien produce, en los individuos, un consensus de interés, donde la noción de consensus resalta la condición de que el interés común sea percibido u observado por los individuos como exigencia de su interés privado ${ }^{22}$, único modo en que es posible que se genere en los individuos un nuevo sentimiento de necesidad, ahora por el interés común. Para Hume, en efecto, no existiría la sociedad si los individuos no tuviesen la experiencia de que el exagerado egoísmo y la limitada bondad de los hombres impide a cada uno alcanzar su bien privado, y de que esto sólo se resuelve mediante la constitución -que es convencional- de la sociedad:

Esto [n. del a.: está hablando de la superación de las perturbaciones que acaecen en la sociedad como consecuencia de la inestabilidad en la posesión de los bienes externos] no puede suceder más que por una convención realizada entre todos los miembros de la sociedad, con el fin de conceder estabilidad a la posesión de los bienes externos y permitir a cada uno el disfrute pacifico de lo que puede adquirir por su fortuna e industria. Por este medio, todo el mundo conoce lo que puede poseer con seguridad, y las pasiones son dominadas en sus movimientos parciales $y$ contradictorios [n. del a.: que sería el caso del egoísmo exagerado en cuanto impide, en el largo plazo, la consecución del propio bien] [...] En lugar de apartarnos de nuestro propio interés o del de nuestros más próximos amigos, absteniéndonos

\footnotetext{
${ }^{19}$ David Hume. A Treatise of Human Nature, III, ii, 2.

${ }^{20}$ David Hume. A Treatise of Human Nature, III, ii, 2.

${ }^{21}$ Vid. David Hume. A Treatise of Human Nature, III, ii, 2.

22 "Para constituir la sociedad no sólo se requiere que ella sea ventajosa, sino también que los hombres sean sensibles a sus ventajas". David Hume. A Treatise of Human Nature, III, ii, 2.
} 
de apoderarnos de lo que poseen los otros, no hay modo de tener en mejor cuenta estos intereses que por una convención semejante, ya que por de ella hacemos que subsista la sociedad, que es necesaria tanto para el bienestar y existencia de los demás, como para el nuestro ${ }^{23}$.

De este modo, la pasión o sentimiento de necesidad por el interés común es, en consecuencia, lo que nos mueve a actuar en conformidad con ese mismo interés. Y tal interés no consiste en otra cosa que en la conservación de las reglas de justicia que permiten la realización del bien privado. El deber contenido en aquellas reglas, por tanto -según la opinión de MacIntyre ${ }^{24}$-, sólo tiene sentido en términos de interés común o consensus de interés, y expresa la conformidad de la regla con aquél interés común, por una parte, y la necesidad de la conducta contenida en la regla para el mismo interés común, por la otra.

Esta explicación de la noción de deber jurídico en Hume es de vital importancia para la discusión que nos ocupa ya que, si se admite la tesis de MacIntyre, entonces pierde fuerza la explicación que los analíticos han dado de la teoría de la justicia en Hume: para Nowell-Smith o Hare, en efecto, el juicio de deber contenido en una norma concreta de justicia (por ejemplo, 'se debe hacer $X$ '), procede de una constatación de hecho ('es de interés común hacer $X$ '), pero la consecuencia lógica sólo es posible si aquella constatación de hecho opera como premisa menor en un silogismo en el que la premisa mayor es también un juicio moral, de contenido más general (en el ejemplo propuesto, 'se debe hacer lo que es de interés común' $)^{25}$. De esta manera, el razonamiento moral quedaría constituido del siguiente modo: (premisa mayor) se debe hacer lo que es de interés común; (premisa menor) $X$ es de interés común; (conclusión) se debe hacer $X$. Así, mientras toda la carga de la justificación del deber se lo lleva la premisa mayor -de la que habrá de ocuparse la filosofía moral-, no hay dificultad ninguna en la conexión del hecho ( $X$ es de interés común) con la norma (se debe hacer $X$ ), puesto que ella no implica una inferencia ilícita de los hechos a las normas, toda vez que el hecho en cuestión ha quedado integrado en un supuesto comprendido por una norma más amplia ${ }^{26}$.

Que éste es el modo de razonar de Hume quedaría claro, para los analíticos ${ }^{27}$, en la crítica del escocés a la tesis de Wollaston, según la cual toda inmoralidad es reductible a la mentira. Hume, en efecto, concede en parte el argumento de Wollaston, pero sostiene que falla en la fundamentación última del deber moral: "[u]na persona desagradecida con su bienhechor afirma, de algún modo, que nunca ha recibido su

\footnotetext{
${ }^{23}$ David Hume. A Treatise of Human Nature, III, ii, 2.

${ }^{24}$ Vid. A. C. MacIntyre. "Hume on 'Is' and 'Ought", p. 457.

${ }^{25}$ Vid., por ejemplo, P. H. Nowell-Smith. Ética, pp. 53-56; R. M. Hare. El lenguaje de la moral, pp. 46-47.

${ }^{26}$ Vid. Philippa Foot. "Moral Arguments". En Mind vol. LXVII, n. 268, p. 504-505.

${ }^{27}$ Vid. W. D. Hudson. La filosofía moral contemporánea, p. 247.
} 
favor. Pero, ¿de qué modo? ¿Es que su deber consiste, acaso, en ser agradecido? Esto supone, no obstante, la existencia de una regla moral anterior"28.

El razonamiento de Hume, en efecto, se articula del siguiente modo: si el deber de ser agradecido se concluye del hecho de que el desagradecimiento supone una falsedad o mentira (la de que el desagradecido no ha recibido el favor de su bienhechor), entonces damos un salto lógico inadecuado desde el es al debe, pues no hemos justificado que aquella falsedad o mentira sea inmoral o contraria al deber: "[c]oncederé, si así se quiere, que toda inmoralidad consiste en esta supuesta falsedad de la acción, pero exijo, como única condición, que se me presente una razón plausible de por qué semejante falsedad es inmoral" ${ }^{29}$. De este modo, la conclusión (de que se debe ser agradecido) sólo podría obtenerse si el razonamiento estuviese presidido por una premisa mayor que afirmase que no se debe mentir, de manera que el razonamiento moral de Hume mantendría la estructura propuesta por Hare: puesto que no se debe mentir, y que ser desagradecido es una forma de mentir, entonces se concluye -con implicación lógica (entailment)- que no se debe ser desagradecido. El hecho de que este argumento se encuentre en el mismo parágrafo del texto sobre el 'is' y el 'ought', parecería apoyar la lectura analítica del mismo texto ${ }^{30}$.

Ahora bien, si se admite la tesis de MacIntyre, de que el deber, en Hume, debe ser entendido en términos de interés común -porque expresa la experiencia de la necesidad de que nuestra conducta se ajuste a dicho interés para hacer posible la consecución del bien privado-, entonces no tiene sentido proponer una premisa mayor como 'debe hacerse lo que es de interés común', ya que se trataría de una proposición tautológica o circular, que no diría más que 'debe hacerse lo que debe hacerse' o 'es de interés común lo que es de interés común'. La crítica de Hume a Wollaston no derribaría esta tesis porque, para el escocés, la proposición ' $X$ es de interés común' sería radicalmente distinta de la proposición ' $X$ es mentira': mientras esta última sería un juicio de hecho del cual no se puede inferir ningún imperativo moral, a no ser que se admita una premisa implícita de contenido moral más amplio ('no se debe mentir'), la primera, en cambio, aunque es también un juicio de hecho, lo sería de un hecho de tal naturaleza que se halla intrínsecamente asociado al deber, de modo que permite la inferencia directa de un juicio moral o de deber (' $X$ es de interés común', luego, 'se debe hacer $X$ '). En otras palabras, mientras la proposición 'no se debe mentir' es una proposición que exige algún tipo de justificación, porque el predicado no está necesariamente exigido por el sujeto, la proposición 'se debe hacer lo que es de interés común' sería una proposición tautológica, ya que el deber sólo puede ser explicado en términos de interés común. Hudson critica esta tesis de MacIntyre afirmando que, en Hume, no está suficientemente distinguido el orden lógico del psicológico y que, allí donde MacIntyre lee una consecuencia lógica, no hay

\footnotetext{
${ }^{28}$ David Hume. A Treatise of Human Nature, III, i, 1, nota 66.

${ }^{29}$ David Hume. A Treatise of Human Nature, III, i, 1, nota 66.

${ }^{30}$ Vid., por ej., A. N. Prior. Logic and the Basis of Ethics, pp 56-58.
} 
más que un nexo psicológico. En otras palabras, la tesis de Hume sobre la relación del interés común con el deber consistiría, según Hudson, en la afirmación de que las reglas de justicia no serán aceptadas (nexo psicológico) mientras no se observe su vínculo con el interés común, y no que no existen (nexo lógico) si no se observa tal vínculo ${ }^{31}$.

Aunque no por la misma vía argumental que Hudson, también Scott-Taggart es crítico con este aspecto de la interpretación de MacIntyre. Para el profesor de Cambridge, en Hume "el fenómeno ético primario es un sentimiento peculiar de aprobación" ${ }^{32}$ y sólo en él se funda -o, más bien, con él se identifica- el deber. Otra cosa es que, de hecho, resulte que lo que aprobamos es aquello que nos aparece como útil, y que de la utilidad individual pasemos a la utilidad social o interés común, como condición de la primera. Pero la sola utilidad, sostiene Scott-Taggart, ya sea individual o social, no es más que un hecho que, como tal, es objeto de la razón, y no del sentimiento. Y lo que Hume estaría argumentando en toda la sección primera de la primera parte del libro III del Treatise es, precisamente, que la moral no se funda en los objetos ni en las relaciones entre objetos que descubre la razón, sino tan sólo en sentimientos y objetos de sentimientos. En esta perspectiva, la argumentación de MacIntyre sobre la importancia de la relación del deber con el interés común debería ser entendida en términos de la reflexión racional sobre unas condiciones morales previas, de modo que la referencia al interés común sirve como criterio de identificación del correcto uso del término deber, pero no como fundamento del mismo ${ }^{33}$.

\section{El deber como hecho}

Una segunda crítica de la interpretación analítica de Treatise III, i, 1 fue desarrollada, principalmente, por el profesor de metafísica y lógica de la Universidad de St. Andrews: Geoffrey Hunter ${ }^{34}$. Concede, Hunter, los dos supuestos interpretativos

${ }^{31}$ Vid. W. D. Hudson. La filosofía moral contemporánea, p. 247; W. D. Hudson. "Hume on Is and
Ought", en The Philosophical Quarterly vol. XIV, n ${ }^{\circ} 56,1964$, pp. 249-250.
${ }^{32}$ M. J. Scott-Taggart. "MacIntyre's Hume", p. 241 .
${ }^{33}$ Vid. M. J. Scott-Taggart. "MacIntyre's Hume", p. 243. Sobre esta cuestión, Jonathan Harrison añade
una distinción entre la naturalidad de la regla de justicia y la artificialidad de la obediencia a la regla
de justicia, afirmando que, en Hume, la regla de justicia se funda -como sostiene MacIntyre- en la
necesidad que el individuo tiene de las condiciones para alcanzar su propio interés, por mediación del
interés común que se expresa en aquellas reglas. No obstante, dice Harrison, para Hume no es lo mismo
el fundamento de la regla de justicia en sí misma y el fundamento de la obediencia a la regla, esto es,
del deber. El individuo siente naturalmente la necesidad de que existan reglas de justicia, pero no es
impelido naturalmente a obedecerlas. Consecuentemente -y contra la opinión de MacIntyre-, Harrison
niega que, en Hume, el deber se pueda inferir de aquella necesidad original. [Vid. Jonathan Harrison:
Hume's Theory of Justice. Clarendon Press, Oxford, 1981, pp. 173 y ss.]. Este autor ofrece su propia
interpretación del pasaje sobre el 'is' y el 'ought' en otra obra: Hume's Moral Epistemology [Clarendon
Press, Oxford, 1976, pp. 69-82].
${ }^{34}$ Vid. Geoffrey Hunter. "Hume on Is and Ought", en Philosophy vol. XXXVII, n`140, 1962, pp. 148- 
esenciales de la lectura analítica del texto de Hume: que el escocés tiene en mente el principio de que 'todo argumento no deductivo resulta defectuoso', por una parte; y que el sentido de 'deduction' es estricto, esto es, que debe ser entendido en términos de implicación lógica (entailment), por la otra. Pero mantiene, el profesor de St. Andrews, la opinión de MacIntyre de que la frase "parece completamente inconcebible" no debe ser entendida en forma irónica, como pretende la interpretación analítica. ¿Cómo hace, entonces, para sostener la tesis de que Hume deduce el deber a partir del ser? Mediante la reducción de los juicios de deber a juicios de ser, en lo cual Hunter lleva al extremo una de las premisas de la argumentación de MacIntyre. Este último había afirmado que el deber expresa una pasión: la necesidad del interés común, y que es, por tanto, desde la experiencia de esa pasión que se infiere -por una vía no deductiva- nuestro deber concreto. Hunter dará un paso más y llegará a afirmar que la noción de deber -en Hume- no es más que informativa de la pasión en cuestión, esto es, que el juicio moral simplemente enuncia el hecho de que el objeto $X$ produce en el sujeto el sentimiento $Y$. De este modo, Hume estaría afirmando que las proposiciones unidas por la cópula debe (ouhgt-propositions) son una sub-clase de las proposiciones unidas por la cópula es (is-propositions), y que tienen la función de referir a un determinado tipo de hechos, esto es, a aquellos hechos que consisten en la generación de cierta clase de sentimientos por cierta clase de objetos.

Hunter funda esta tesis en varios textos del escocés. Entre ellos, uno que se halla casi contiguo al comentario sobre el 'is' y el 'ought' que ha suscitado el debate. En efecto, dice Hume poco antes de aquél comentario: "cuando se sostiene que cualquier acción o carácter son viciosos, no se significa nada más que, por la condición de la propia naturaleza, se tiene un sentimiento de reproche cuando se los contempla" ${ }^{\prime 3}$. Y añade, en otro lugar:

La distinción entre el bien y el mal moral se funda en el placer o dolor que resulta de la presencia de un sentimiento, y como el placer y el dolor no pueden ser ignorados por la persona que los experimenta, se sigue, precisamente, que existe tanto vicio y virtud en un carácter cuanto cada uno pone en él [según sus sentimientos], $y$ que es imposible que alguna vez nos equivoquemos en esta materia ${ }^{36}$.

De donde se seguiría, según Hunter, que la condición virtuosa o viciosa de una acción, en la mente de Hume, no dependería más que de los sentimientos singulares que esa acción despierta en los distintos individuos. Y si la virtud y el vicio se identifican con el sentimiento de aprobación o reproche que un determinado objeto despierta en el suje-

152; Geoffrey Hunter. “A Replay to Professor Flew”, en Philosophy vol. XXXVIII, n 144, 1963, pp. 182-184.

${ }^{35}$ David Hume. A Treatise of Human Nature, III, i, 1.

${ }^{36}$ David Hume. A Treatise of Human Nature, III, ii, 8. 
to, entonces también el deber se define por esa identificación con el sentimiento, como parecerían probar otros textos de Hume: "[1] a obligación natural respecto a la justicia, esto es, al interés, ha sido plenamente explicada; pero en cuanto a la obligación moral o al sentimiento de lo bueno y lo malo..." ${ }^{37}$ o, poco más adelante:

Toda la moralidad depende de nuestros sentimientos, y cuando una acción o cualidad del espíritu nos agrada de un cierto modo, decimos que es virtuosa, y cuando su olvido o no realización nos desagrada, de una manera análoga decimos que nos hallamos bajo la obligación de realizarla. Un cambio en la obligación supone un cambio en el sentimiento, y la creación de una nueva obligación supone la aparición de algún nuevo sentimiento ${ }^{38}$.

Consecuentemente, no habría ninguna dificultad -en Hume- para deducir las proposiciones de deber a partir de las proposiciones de ser o de hecho. No hay salto lógico indebido, porque la proposición de deber no hace más que enunciar una determinada situación fáctica, que podría ser formulada en una proposición de ser. En este punto, hay quien va un paso más allá, y sostiene que -siempre en Hume- la deducción del ser al deber es innecesaria puesto que la sola información, en el juicio moral, del sentimiento de aprobación o reproche es todo lo que se necesita para la acción moral. Hudson atribuye erróneamente esta posición a Hunter ${ }^{39}$, quien la enuncia pero, atribuyéndola al profesor G. Ryle -considerado el iniciador de la escuela analítica de Oxford-, se aparta de ella ${ }^{40}$. Yalden-Thomson, en cambio, la asume como propia: "[Hunter] afirma que la segunda interpretación le fue sugerida por el profesor Ryle y ella es, pienso, la correcta" ${ }^{41}$. Una posición próxima a la descrita es la de M. J. Scott-Taggart ${ }^{42}$.

De cualquier modo, a partir de la crítica que recibe de Antony $\mathrm{Flew}^{43}$, Hunter precisa un aspecto de esta tesis, en el sentido de que la posibilidad de deducir el deber a partir del ser, en Hume, no se extiende a cualquier proposición de ser, sino sólo a aquellas constataciones fácticas referidas a los sentimientos humanos, de manera que la ley de Hume existiría -en el propio Hume-, pero sólo en relación a la imposibilidad de deducir el deber a partir de juicios de hecho sobre objetos externos o relaciones de razón ${ }^{44}$. De aquí que la crítica de Hume a los sistemas de moral que le precedieron radicaría -según

\footnotetext{
${ }^{37}$ David Hume. A Treatise of Human Nature, III, ii, 2. (El destacado es nuestro).

${ }^{38}$ David Hume. A Treatise of Human Nature, III, ii, 5.

${ }^{39}$ Vid. W. D. Hudson. La filosofía moral contemporánea, p. 241.

${ }^{40}$ Vid. Geoffrey Hunter. "Hume on Is and Ought", p. 150.

${ }^{41}$ D. C. Yalden-Thomson. "Hume's View of 'Is-Ought"” en Philosophy vol. LIII, n 203, 1978, pp. 91-92.

${ }^{42}$ Vid. M. J. Scott-Taggart. "MacIntyre's Hume”, p. 244.

${ }^{43}$ Vid. Antony Flew. "On the Interpretation of Hume", en Philosophy vol. XXXVIII, n 144, 1963, pp. 178-182.

${ }^{44}$ Vid. Geoffrey Hunter. “A Replay to Professor Flew”, p. 183.
} 
la interpretación que Hunter hace del texto de Treatise III, i, 1- en la afirmación de que estos sistemas intentaron deducir el deber, ya a partir de verdades necesarias y eternas conocidas por la razón, ya a partir de la voluntad de Dios.

Sobre la base de estas dos líneas argumentales para discutir la lectura analítica del párrafo que ha dado nombre a la ley de Hume -una iniciada por MacIntyre y la otra por Hunter-, la discusión se ampliaría considerablemente, tanto en lo relativo a la atribución de la ley al propio Hume, como a los aspectos sustantivos de la cuestión, que hacen referencia a la posibilidad de inferir -o no- el deber a partir del ser. Así, por ejemplo, el profesor de Cornell, Max Black, en "The Gap between 'Is' and 'Should"' 45 , cogería el hilo del razonamiento de MacIntyre -aunque apartándose de la interpretación que éste hace del texto de Hume-, para sostener la posibilidad de la inferencia cuestionada. En este artículo, de hecho, Black propone el otro nombre con que la ley de Hume ha pasado a la historia: la guillotina de Hume, y termina refiriéndose a ella como un "dogma que

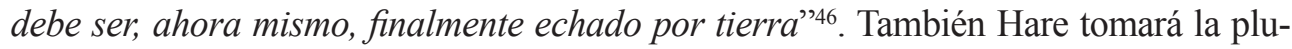
ma para manifestar su abierto rechazo, tanto a la argumentación de MacIntyre y Black sobre el fundamento y significado del deber, como a la singular interpretación que hace MacIntyre del texto de Treatise III, i, 1, reafirmando la suya propia ${ }^{47}$.

\section{El pasaje del 'is' y el 'ought' en el contexto de Treatise III, i, 1: la razón no mueve a la acción ni es causa de la obligación.}

Finalmente, conviene atender a una consideración introducida por el profesor norteamericano David Broiles, que enfrentaría derechamente la cuestión en el capítulo VI de su The Moral Philosophy of David Hume ${ }^{48}$. Broiles, aunque también se aparta de la interpretación analítica del pasaje de Hume, comienza por criticar la lectura hecha por MacIntyre, que estima completamente insatisfactoria. Y, en primer lugar, su crítica se dirige a la débil base textual sobre la que intenta poner pie MacIntyre ${ }^{49}$ : para que su interpretación sea posible, como ya se ha dicho, es necesario leer el pasaje final de Treatise III,i,1 como si Hume estuviese, en él, proponiendo un problema o haciendo una pregunta que luego responderá. De aquí la necesidad de leer aquel "parece completamente inconcebible" en un sentido literal y no irónico, de manera que, en realidad, lo que parece inconcebible no lo es, sino que tiene que ser debidamente explicado. Tal condición de la interpretación de MacIntyre (que también es exigida por la que propone Hunter), sostiene Broiles, no se condice con el contexto de la frase en cuestión, ya que Hume comienza el párrafo advirtiendo que quiere hacer una observación, y no plantear

\footnotetext{
${ }^{45}$ Vid. Max Black. "The Gap between 'Is' and 'Should'”, pp. 165-181.

${ }^{46}$ Max Black. "The Gap between 'Is' and 'Should”, p. 181.

${ }^{47}$ R. M. Hare. "The Promising Game”, en Revue Internationale de Philosophie 70, 1964, pp. 398-412.

${ }^{48}$ Vid. David Broiles. The Moral Philosophy of David Hume. Martinus Nijhoff, The Hague, 1969, pp. 85-94.

${ }^{49}$ Vid. David Broiles. The Moral Philosophy of David Hume, 1969, p. 88.
} 
una pregunta o problema, y la frase del "parece completamente inconcebible" es casi inmediatamente continuada por la afirmación de que las nuevas relaciones que expresa la cópula 'debe-no debe' son enteramente diferentes de aquellas que expresa la cópula 'es-no es', lo cual no parece dejar mucho espacio para que de estas últimas se infieran las primeras. En este punto, Broiles es secundado por otro importante estudioso de la filosofía moral de Hume, ya citado: Jonathan Harrison, que, aunque sin referirse directamente a MacIntyre, descarta sin rodeos su propuesta interpretativa del "parece completamente inconcebible" por considerarla inconsistente con otras frases del mismo párrafo como aquella de que "esta pequeña atención [al salto del 'is' al 'ought'] bastaría para subvertir todos los sistemas vulgares de moral" ${ }^{50}$.

Pero más importante es la crítica que Broiles hace al fondo de la argumentación de MacIntyre ${ }^{51}$ : ésta, como la interpretación analítica, no sería coherente con el resto de la obra moral de Hume. En opinión de Broiles, la afirmación de que, en Hume, el deber moral puede ser inferido de constataciones racionales de hecho -como sostiene MacIntyre- es errónea, pero no porque en tal inferencia Hume viole su propia prohibición de proceder de premisas fácticas a conclusiones morales -como pretende la interpretación analítica-, sino porque tal inferencia sería inconsistente con la doctrina que ha desarrollado en la sección primera de la primera parte del libro III, que no se refiere al problema del naturalismo o anti-naturalismo, sino a la imposibilidad de que el deber, o la obligación, sea derivado de la razón. El argumento central de aquella primera sección, dice Broiles, se podría sintetizar en el siguiente silogismo:

“(1) Los juicios morales, las reglas y los preceptos excitan las pasiones y producen o previenen acciones.

(2) La razón, por sí misma, no excita las pasiones ni produce o previene acciones.

(3) Luego, las reglas de la moral no son conclusiones de la razón"52.

Todo el argumento de la sección, añade, es dependiente de la reducción humeana de la obligación a los motivos que causan la acción, y se orienta a demostrar que la razón nunca mueve a la acción por sí misma, de manera que la consideración de un juicio como verdadero, que es lo propio de la razón, nunca puede ser constitutivo de un deber. Así, por ejemplo, los juicios sobre la naturaleza o la voluntad de Dios, aun siendo probadamente verdaderos, no ofrecen ningún motivo para la acción $\mathrm{y}$, por tanto, no pueden ser constitutivos de un deber. Hasta aquí, podría parecer que la lectura de Broiles es coincidente con la de los analíticos, pero se advierte rápidamente que no existe tal coincidencia si se atiende al hecho de que la imposibilidad de derivar la obligación desde la razón es absoluta, esto es, se extiende también a aquellos

\footnotetext{
${ }^{50}$ Vid. Jonathan Harrison. Hume's Moral Epistemology, pp. 69-70.

${ }^{51}$ David Broiles. The Moral Philosophy of David Hume, p. 89.

${ }^{52}$ David Broiles. The Moral Philosophy of David Hume, 1969, p. 4.
} 
juicios racionales que tienen contenido moral. Es decir, la sola afirmación que algo es verdadero, incluso si ese algo es de naturaleza moral, no proporciona un motivo para la acción, ni constituye, en consecuencia, un deber u obligación.

Retomando el ejemplo empleado más arriba, se puede considerar la diferencia entre la interpretación de Broiles y aquellas de Hare o Nowell-Smith, por una parte, y MacIntyre, por la otra. Los primeros dirían: la proposición 'se debe hacer $X$ ' se puede derivar de la proposición ' $X$ es de interés común' si, y sólo si, existe una premisa mayor de contenido moral como 'se debe hacer lo que es de interés común'; MacIntyre, en tanto, afirmaba que tal premisa mayor es innecesaria, porque el deber se identifica con el interés común, de manera que del juicio ' $X$ es de interés común' se puede inferir directamente que 'se debe hacer $X$ '. Lo que vendría a sostener Hume, en cambio -siempre según la interpretación de Broiles-, sería que ni la proposición 'se debe hacer lo que es de interés común' ni el juicio ' $X$ es de interés común', considerados simplemente como verdades de la razón, pueden servir de bases para derivar la existencia de un deber concreto, porque "para Hume, uno tiene una obligación sólo si tiene un motivo o inclinación hacia la realización de aquella clase de acción"53.

En tal sentido, la teoría humeana de la justicia -que ha traído a colación MacIntyre en su favor- demostraría, en efecto, que la interpretación analítica sería errónea, pero no porque en ella haya una inferencia de los hechos a las normas, sino porque Hume muestra que los deberes jurídicos existen en la medida en que el propio interés (que, como motivo último de toda acción, es constitutivo de la obligación natural originaria) se traslada al e identifica con el interés común. Así, si no hubiese un motivo (esto es, una pasión que mueva a la voluntad) para hacer lo justo, no habría, tampoco, ninguna obligación, por más verdades que fuesen conocidas o se dijesen sobre la naturaleza de la justicia. De este modo, el deber u obligación no es más que un hecho de la naturaleza humana cuyo conocimiento se manifiesta en los juicios morales, pero que no se infiere ni se deduce en absoluto de alguna verdad poseída por la razón ${ }^{54}$. A partir de esta lectura del conjunto de Treatise III, i, 1, Broiles concluye que el alegato de Hume contenido en el pasaje discutido se dirige a los racionalistas, que señalan relaciones cuyo conocimiento daría razón de la naturaleza del bien y del mal, pero que no muestran ningún motivo que justifique que el agente deba hacer lo que es bueno, o dejar de hacer lo que es malo. Procura demostrar, Broiles, que Hume tenía en mente, especialmente, a tres autores morales del racionalismo británico: Ralph Cudworth ${ }^{55}$, Samuel Clarke ${ }^{56}$ y William Wollaston ${ }^{57}$. Es en este último punto en el que la intervención de Broiles cobra importancia para entender la posterior

\footnotetext{
${ }^{53}$ David Broiles. The Moral Philosophy of David Hume, p. 89.

${ }^{54}$ Vid. David Broiles. The Moral Philosophy of David Hume, pp. 90-93.

${ }^{55}$ Vid. David Broiles. The Moral Philosophy of David Hume, pp. 9-10.

${ }^{56}$ Vid. David Broiles. The Moral Philosophy of David Hume, pp. 11-12.

${ }^{57}$ Vid. David Broiles. The Moral Philosophy of David Hume, pp. 13-14.
} 
argumentación de John Finnis, ya que éste se sumará a la disputa prolongando el argumento del norteamericano e intentando demostrar que las razones de Hume se dirigían, singularmente, a atacar la doctrina moral de Samuel Clarke.

En opinión de este filósofo del derecho y profesor de Oxford australiano, una lectura atenta del pasaje de Hume -y en el contexto del conjunto del Treatise- revelaría que la intención del escocés se dirige, más que a la negación de la posibilidad de la inferencia en cuestión, a criticar la teoría moral de ciertos racionalistas que precedieron al propio Hume, como Vásquez, Suárez, Grocio, Clarke y Butler ${ }^{58}$, para quienes el conocimiento racional de las cualidades morales de las acciones bastaría para mover a la acción, de modo que el razonamiento moral operaría del mismo modo que el de las ciencias ${ }^{59}$. Finnis estima que Hume atiende, especialmente, a las opiniones morales de Samuel Clarke ${ }^{60} \mathrm{y}$, sobre esta base, procura complementar el trabajo de Broiles aportando algunos textos del propio Clarke que parecen haber sido hechos a la medida del comentario final de Treatise III, i, 1 .

Así, por ejemplo, el australiano cita el siguiente párrafo de A Discourse Concerning the Uncheangeable Obligations of Natural Religion, que publicase Clarke en 1706:

"[i]Las mismas diferentes relaciones necesarias y eternas, que guardan entre sí diferentes cosas; en atención a las cuales [ii] la voluntad de Dios siempre y necesariamente se determina a sí misma, para elegir obrar sólo lo que es conforme con [las reglas eternas de] la justicia, la equidad, la bondad y la verdad, para el bienestar de todo el universo; [iii] deben asimismo determinar constantemente las voluntades de todos los seres racionales subordinados, para dirigir todas sus acciones según las mismas reglas, en orden al bien público, en sus posiciones respectivas. Esto es; [i] estas diferencias eternas y necesarias entre las cosas hacen conveniente y razonable para las criaturas actuar así; ellas [iii] causan que su obrar así sea su deber, o les imponen una obligación; aun dejando aparte la consideración de que estas reglas sean la voluntad o mandato positivos de Dios[... ${ }^{\prime 61}$.

El argumento de Clarke, según Finnis, sería el siguiente: [i] hay relaciones necesarias y eternas entre las cosas como, por ejemplo, [ii] que la voluntad de Dios se

\footnotetext{
${ }^{58}$ Vid. John Finnis. "Reason, Universality, and Moral Thought", en John Finnis. Reason in Action. Collected Essays: Volume I. Oxford University Press, Oxford, 2011, p. 125. Este trabajo corresponde a una conferencia dictada en 1971 que permaneció inédita hasta 2011, de aquí que la repercusión del australiano en la discusión reseñada sólo comience con Natural Law and Natural Rights, en 1980.

${ }^{59}$ Vid. John Finnis. "Reason, Universality, and Moral Thought".

${ }^{60}$ John Finnis. "Natural Law", en John Finnis. Reason in Action. Collected Essays: Volume I. Oxford University Press, Oxford, 2011, p. 202. (Publicado originalmente bajo el título "Loi Naturelle", en Monique Canto-Sperber (ed.). Dictionnaire de Philosophie Morale. Presses Universitaires de France, Paris, 1996, pp. 862-868).

${ }^{61}$ Citado por John Finnis. Ley natural y derechos naturales. Traducción y estudio preliminar de Cristóbal Orrego, Abeledo-Perrot, Buenos Aires, 2000 p. 72. Los énfasis son del propio Clarke, la numeración es de Finnis, que conservamos en orden a la explicación que el australiano hace del texto.
} 
autodetermina a elegir lo que es bueno, recto, etc. Como no es razonable ni conveniente obrar contra la razón eterna de las cosas, entonces [iii] aquella razón causa el deber u obligación, y así gobierna todas las acciones de los hombres ${ }^{62}$.

Si se trae a la memoria el famoso pasaje de Hume, se podrá admirar la casi perfecta correspondencia entre la crítica del escocés y la argumentación de Clarke. Dice Hume: "el autor procede por algún tiempo según el modo ordinario de razonar y establece la existencia de Dios, o hace observaciones sobre las cosas humanas", que es exactamente lo que hace Clarke en el punto [ii] de su discurso. Continúa Hume: "mas súbitamente me sorprendo al encontrar que, en lugar de las cópulas habituales de las proposiciones, es-no es, no encuentro ninguna proposición que no está enlazada por un debe-no debe", precisamente lo que sucede en el punto [iii] del argumento del racionalista británico. Alega el escocés: "este debe-no debe expresa una nueva relación, que ha de ser observada y explicada", porque, en efecto, en [i] Clarke ha dejado claro que está tratando de diferentes relaciones necesarias y eternas entre las cosas que, en todo caso, pueden manifestar la conveniencia o razonabilidad de ciertas acciones, pero que nada dicen acerca de su obligatoriedad, ya que ésta es una nueva relación que no estaba contenida en las anteriores. De aquí que "debe darse una razón para algo que parece completamente inconcebible: cómo esta nueva relación puede ser una deducción de otras que son enteramente diferentes de ella", razón que no aparece en ningún sitio del punto [iii] de la argumentación de Clarke, por lo que estaría dando un salto injustificable de unas proposiciones a otras, como se manifestaría singularmente en el segundo punto [iii] del texto citado por Finnis, en que afirma que la conveniencia y razonabilidad de ciertas acciones -consecuencia de relaciones eternas y necesarias entre las cosas- causa el deber de obrar en conformidad con aquella conveniencia o razonabilidad.

Siguiendo el argumento delineado por Broiles, el oxoniense sostiene que el núcleo de la crítica de Hume se dirige al hecho de que Clarke, al tratar de la obligación, se desentiende del motivo de la acción, de aquello que es causa eficaz para que el sujeto actúe, dado el supuesto -central en la filosofía moral del escocés, y al cual dedica toda la primera sección de la primera parte del libro III- de que ni la razón, ni las relaciones por ella conocidas, son capaces de mover directamente a la voluntad.

Con ello -dice Finnis ${ }^{63}$ - cae la interpretación propuesta por la filosofía analítica, ya que la cuestión de un motivo eficaz para mover a la voluntad -con el que quedará identificado el deber- es una cuestión de hecho. El salto que Hume criticaría en los racionalistas, consecuentemente, no es el salto entre las constataciones fácticas y los juicios morales, o entre el ser y el deber, o entre el hecho y la norma, sino que está criticando el salto entre verdades de la razón, cualquiera sea su naturaleza (esto es, incluso verdades morales o normativas) y conclusiones sobre lo que debe hacerse, esto es, sobre lo que es motivo eficaz de la ac-

\footnotetext{
${ }^{62}$ Vid. John Finnis. Ley natural y derechos naturales, pp. 72-73.

${ }^{63}$ Vid. John Finnis. Ley natural y derechos naturales, pp. 74-75.
} 
ción. En un trabajo bastante posterior, el profesor australiano ofrece una síntesis muy clara de lo que sería el auténtico pensamiento de Hume en esta materia: "[e]l es de 'es lo que, en este momento, más deseo', como el es de 'es de lo que estaba más deseoso hasta hace un momento' (y, por lo demás, el es de 'mi inteligencia es de la clase que encuentra medios para los fines"), no otorga fundamentos para un deber"64.

En apoyo de esta interpretación, Finnis propone un texto del Treatise, en la misma sección 1, parte i, libro III, y muy poco anterior a aquél en que propondría, según la interpretación analítica, la inderivabilidad del deber a partir del ser. Dice Hume:

Una cosa es conocer la virtud y otra es conformar la voluntad a ella. En consecuencia, para probar que las reglas de lo correcto y lo incorrecto son leyes eternas y obligatorias para toda mente racional, no es suficiente mostrar las relaciones sobre las que se fundan: debemos también poner de relieve la conexión entre la relación y la voluntad; y debemos probar que esa conexión es tan necesaria que en cualquier mente bien dispuesta debe presentarse y tener influencia; a pesar de que la diferencia entre las mentes sea, en otros aspectos, inmensa e infinita. Ahora bien, ya he probado que, en la naturaleza humana ninguna relación puede producir por sí misma una acción [...] y no podemos probar a priori que estas relaciones, si existen realmente y son percibidas, sean universalmente forzosas y obligatorias ${ }^{65}$.

En este texto, indica Finnis, aparece nítidamente la identificación humeana entre eficacia y obligatoriedad y, habida cuenta de que la eficacia es una cuestión de hecho, implicaría una contradicción con el pasaje del 'is' y el 'ought', si es que éste último es interpretado en el sentido que han propuesto los analíticos. Hume estaría violando la regla lógica que él mismo propone, y lo estaría haciendo, además, apenas cuatro párrafos antes de aquél en que la propone ${ }^{66}$. Por el contrario, si se asume la lectura indicada por Broiles y seguida por Finnis, no habría contradicción en Hume, sino perfecta coherencia (aunque el australiano, desde luego, advierta otras contradicciones y carencias en la solución que Hume ofrece al problema de la justificación del deber ${ }^{67}$ ).

\section{Breve nota conclusiva}

Evidentemente, la discusión sobre el auténtico sentido del pasaje final de Treatise III, i, 1 no se congela en el punto de la intervención de Finnis ${ }^{68}$, como atestiguan las

\footnotetext{
${ }^{64}$ John Finnis. "Practical Reason's Foundations", en John Finnis. Reason in Action. Collected Essays: Volume I. Oxford University Press, Oxford, 2011, p. 23. (Publicado originalmente como "Foundations of Practical Reason Revisited", en The American Journal of Jurisprudence 50, 2005, pp. 109-132).

${ }^{65}$ David Hume. A Treatise of Human Nature, III, i, 1.

${ }^{66}$ Vid. John Finnis. "Natural Law", p. 202.

${ }^{67}$ Vid. John Finnis. Ley natural y derechos naturales, pp. 73-75.

${ }^{68}$ Aunque quizá sí se pueda decir que la opinión del australiano sobre la cuestión caló hondo -y ad-
} 
incontables argumentaciones posteriores que han seguido alimentando esta disputa sobre los alcances de la filosofía moral de David Hume: autores de referencia para los estudios de la obra del escocés -como Mackie ${ }^{69}$, Cohen $^{70}$, Capaldi ${ }^{71}$ o Darwall ${ }^{72}$, entre otros- han vuelto sobre esta cuestión. En lo que toca a estas páginas, especial mención merece, de entre los autores señalados, Nicholas Capaldi, puesto que realiza una durísima crítica a la lectura analítica de la obra de Hume, afirmando que tal escuela, a partir de presupuestos que no estaban en el horizonte del filósofo escocés, impone una serie de dogmas sobre su filosofía que la encorsetan y deforman, para adecuarla y aproximarla a las bases esenciales de las principales tesis analíticas. Del pasaje sobre el 'Is' y el 'Ought' en particular, llega a decir que la lectura analítica "se destaca como la más flagrante tergiversación del texto de Hume" " Sin embargo, aunque las nuevas intervenciones añaden precisiones argumentales valiosas, o algún interesante dato filológico o histórico que colabora en el desentrañamiento del auténtico sentido que Hume dio a Treatise III, 1, i, lo cierto es que no suponen una novedad relevante en lo que toca a los problemas filosóficos centrales que se encierran detrás de la difícil interpretación del dicho texto. El propio Finnis, aunque volviese sobre la cuestión en diversas oportunidades, no volvería a añadir elementos sustantivos a esta cuestión ${ }^{74}$.

Por ello es que la exposición de la discusión hasta el momento de la intervención del australiano permite -tal como se adelantaba al comienzo de este trabajo- una síntesis sistemática de las grandes cuestiones con las que un filósofo moral debe lidiar cuando trata de aquella regla lógica que -por influencia del movimiento analítico- ha llegado a ser conocida como ley de Hume. En nuestra opinión, la magnitud y variedad de los argumentos que se han opuesto a la atribución de la ley en cuestión al empirista escocés hace muy difícil persistir en aquella interpretación analítica de Treatise III, 1, i. Pero mucho más interesante que esta conclusión interpretativa nos

quirió la categoría de solución cuasi-definitiva del problema- entre muchos autores iusnaturalistas que, ocupados de la objeción presente en la ley de Hume, han tocado lateralmente la cuestión histórica.Vid., por ejemplo, Carlos I. Massini. La falacia de la falacia naturalista. EDIUM, Mendoza, 1995, pp. 61-62; Ana Marta González. Moral, razón y naturaleza. Una investigación sobre Tomás de Aquino. $2^{\mathrm{a}}$ edición, EUNSA, Pamplona, 2006, pp. 42-43.

${ }^{69}$ Vid. J. L. Mackie. Hume's Moral Theory. Routledge and Kegan Paul, Londres, 1980.

${ }^{70}$ Vid. Mendel Cohen. "Obligation and Human Nature in Hume's Philosophy", en The Philosophical Quarterly vol. 40, n 160, 1990.

${ }^{71}$ Vid. Nicholas Capaldi. "The Dogmatic Slumber of Hume Scholarship”, en Hume Studies vol. XVIII, $\mathrm{n}^{\circ} 2,1992$.

72 Vid. Stephen Darwall. "Motive and Obligation in Hume's Ethics”, en Noûs vol. 27, n 4, 1993.

${ }^{73}$ Nicholas Capaldi. "The Dogmatic Slumber of Hume Scholarship", p. 131.

${ }^{74}$ Vid., por ejemplo, John Finnis. "Natural Law", p. 202; también John Finnis. "Commensuration and Public Reason", en John Finnis. Reason in Action. Collected Essays: Volume I. Oxford University Press, Oxford, 2011, p. 242. (Publicado originalmente en Ruth Chang (ed.). Incommensurability, Comparability and Practical Reasoning. Harvard University Press, Londres, 1997, pp. 215-233 y 285-289). 
parece la manifestación de los diversos supuestos sobre los que se configuran unas u otras interpretaciones: no basta la lectura del texto en cuestión para resolver el problema de la atribución a Hume de la ley que prohíbe inferir enunciados morales a partir de premisas fácticas, sino que es necesario descubrir cómo entendía, el propio Hume, los hechos, las normas y los enunciados que describen o presentan unos y otras, entre otras muchas cuestiones relevantes. Del mismo modo, cuando un filósofo moral concede o critica la validez de la ley de Hume -independientemente de su atribución al escocés-, es necesario hacer explícito el sentido en el que entiende los hechos, las normas, los enunciados relativos a unos y otras, etc., porque, de otro modo, esa afirmación o negación de la validez de la regla lógica en cuestión se mantendrá en la ambigüedad de unos fundamentos implícita y hasta inconscientemente asumidos. Un ejemplo claro de la necesidad de esta explicitación de los supuestos a partir de los cuales se entra en estos grandes problemas de la filosofía moral, se puede encontrar, precisamente, en la contemporánea discusión entre el iusnaturalismo y sus críticos analíticos. El más grave defecto de dicha discusión -especialmente de parte de muchos autores iusnaturalistas- es que se enfrentan cuestiones como la validez de la ley de Hume -ya concediéndola, ya rechazándola- sin dar coherentemente razón del modo en que son asumidos los supuestos en los que se juega la dicha validez y dando lugar, así, a graves contradicciones en el conjunto de sus postulados (el propio Finnis es, según nuestra opinión, un nítido ejemplo de estas contradicciones, aunque no cabe hablar de ello en este lugar). De aquí, estimamos, el valor de revisar una discusión como la que se ha presentado en este trabajo.

Felipe Widow LiRA

Pontificia Universidad Católica de Chile

ffwidow@uc.cl 